\title{
MATURIDADE EM GESTÃO AMBIENTAL: REVISITANDO AS MELHORES PRÁTICAS
}

\author{
Bento Alves Costa Filho* \\ costaf@uol.com.br \\ Fernando de Rosa \\ fernando.rosa@uol.com.br \\ *Faculdades Alfa
}

http://dx.doi.org/10.1590/1413.2311.030.59633

Recebido em 28/10/2015

Aprovado em 16/06/2017

Disponibilizado em 07/08/2017

Avaliado pelo sistema "double blind review"

Revista Eletrônica de Administração

Editoras-chefe: Andrea Oltramari e Maria Ceci Misoczky

ISSN 1413-2311 (versão "on line")

Editada pela Escola de Administração da Universidade Federal do Rio Grande do Sul

Periodicidade: Quadrimestral

Sistema requerido: Adobe Acrobat Reader

\section{RESUMO}

Este estudo tem por objetivo avaliar os fundamentos da gestão ambiental em empresas localizadas em Goiás que utilizam as chamadas melhores práticas nesta área. Este estado teve um forte crescimento econômico nas últimas quatro décadas, mas as preocupações na área ambiental não necessariamente acompanharam este desenvolvimento. A avaliação tomou como base modelos de maturidade já utilizados pela literatura, que classificam a competência organizacional em gestão ambiental por meio de estágios que evoluem desde a inexperiência até o pleno domínio sobre o assunto. O trabalho de campo incluiu uma investigação sobre as atividades de três organizações em setores de grande relevância no estado: mineração, alimentos, bebidas e sucroalcooleiro. Foram realizados estudos de caso múltiplos tendo como principais evidências entrevistas, documentos e publicações sobre o assunto. Algumas empresas não se mostraram predispostas a abrir suas informações referentes à gestão ambiental, o que é compreensível uma vez que o tema envolve questões delicadas como a relação entre a organização e seu meio ambiente. Aquelas que se mostraram abertas para discutir o assunto indicaram estarem bem resolvidas em relação à questão. Foi o caso das três empresas objeto dos estudos de caso múltiplos. Os resultados mostraram que as empresas com alto grau de maturidade em gestão ambiental atuam de forma planejada, com estrutura organizacional dedicada e utilizam como referência padrões internacionais rigorosos sobre o tema.

Palavras-Chave: Gestão Ambiental. Impactos Ambientais. Maturidade Ambiental.

\author{
ABSTRACT \\ REAd | Porto Alegre - Edição 86 - Nº 2 - Maio / Agosto 2017 - p. 110 - 134
}


This study aims to assess the fundaments and challenges of the environmental management in companies located in the state of Goias that use the best practices. This Brazilian state had a strong economic growth in the last four decades but concerns about environment did not catch as much attention. The assessment was based on maturity models available in the literature which classify organizational competence in environmental management by stages evolving from inexperience toplain knowledge. Thefield workincluded an investigation using three case studies in industries of relevance in Central Brazil: mining, beverage and sugar-alcohol. The main evidences accessed in the case studies were interviews with key participants, internal documents and publications. Some companies were not predisposed to open up information about environmental management, which was understandable because the issue involves delicate questions like the relationship of an organization and its environment. Those companies that were willing to cooperate indicated they had no conformity problems and were selected to be studied here. The results showed that companies with high degree of environmental management maturity incorporate to their practices good planning and dedicated structure combined with rigorous international standards as reference.

Key-Words: Environmental Management. Environmental Impacts. Environmental Maturity.

\section{RESUMEN}

Este estudio tiene por objetivo evaluar los fundamentos de la gestión ambiental en empresas localizadas en el Estado de Goiás, las cuales utilizan las denominadas mejores prácticas en esta área. Este estado tuvo un fuerte crecimiento económico en las últimas cuatro décadas, sin embargo las preocupaciones en el área ambiental no necesariamente acompañaron este desarrollo. La evaluación tomó como base modelos de madures ya utilizados en estos procedimientos, los cuales clasifican la competencia organizacional en gestión ambiental por medio de etapas que evolucionan desde la inexperiencia hasta el pleno dominio del asunto. El trabajo de campo incluyó una investigación sobre las actividades de tres organizaciones en sectores de gran relevancia en el Estado: explotación minera, alimentos y bebidas y el sector de azúcar y alcohol. Fueron realizados estudios de caso múltiples que tenían como principales elementos de investigación entrevistas, documentos y publicaciones sobre el asunto. Algunas empresas no se mostraron predispuestas a suministrar sus informaciones referentes sobre la gestión ambiental, lo cual es comprensible, dado que el tema implica aspectos delicados en la relación de la organización con el medio ambiente. Aquellas que estuvieron dispuestas a discutir el asunto indicaron que tienen resueltos los aspectos referentes a la cuestión ambiental. Este fué el caso de las tres empresas objeto de los estudios múltiples. Los resultados mostraron que las empresas con alto grado de madures en gestión ambiental actúan de forme planificada, con estructura organizacional especializada y utilizan como referencia padrones internacionales rigurosos sobre el tema.

Palabras-Clave: Gestión Ambiental. Impacto Ambiental. Madures Ambiental.

\section{INTRODUÇÃO}

O papel das empresas em questões ambientais tem sido discutido ao longo das últimas décadas. No início da década de 1950, muito antes de o assunto sustentabilidade tornar-se lugar-comum, Howard R. Bowen (BOWEN, 2013) já admitia que a conservação dos recursos 
naturais fazia parte das responsabilidades dos homens de negócio. El-Ansary (1974) mostrou que a preocupação com o meio ambiente resultou em necessidade de revisão das estratégias de composto de marketing já nos anos 70.

Toda a problemática gerada pelo uso insustentável de recursos naturais para suportar o consumo de produtos tornou a preocupação com o meio ambiente um fator crítico nos negócios. Identificar antecipadamente potenciais situações que possam impor danos irreversíveis à natureza e encontrar meios e ferramentas que permitam atuar sobre esses problemas é o desafio. Ou seja, a gestão empresarial precisou incorporar ao seu planejamento estratégico e operacional variáveis ligadas à questão ambiental. $\mathrm{O}$ consumo de energia por unidade produzida, o controle do volume de resíduos industriais gerados, o monitoramento da legislação ambiental, o tratamento dispensado aos materiais recicláveis, os investimentos e despesas com os aspectos ambientais,a gestão dos planos de emergência, medidas operacionais visando à prevenção e controle da poluição, todas essas são atividades que compõem a gestão ambiental empresarial.

Empresas que adotam práticas socialmente responsáveis podem se diferenciar em relação a outras e obter o que Porter (1991) consagrou na literatura de estratégia como vantagem competitiva. A utilização de práticas socialmente responsáveis pode gerar vantagem competitiva, além de contribuir para uma sociedade melhor (BRUNI et al., 2008).

Neste contexto, o presente estudo teve por objetivo avaliar como se dá a gestão ambiental em empresas industriais que se utilizam das melhores práticas em relação ao tema. A ideia principal é identificar os pontos críticos comuns e não comuns sobre o assunto de modo que se possa ter um melhor quadro em relação aos procedimentos necessários para uma boa atuação na área. Uma das pretensões é que o artigo desperte interesse das empresas que estejam buscando se engajar em atividades que melhorem suas performances na prevenção ambiental de forma sistemática.

Não são muitos os trabalhos no estado de Goiás que abordam a gestão ambiental do ponto de vista empresarial, numa região cujo crescimento econômico tem ocorrido de forma intensa nas últimas décadas. Em termos de participação em relação ao país, o referido estado saiu de 1,6\% do PIB brasileiro em 1970 para 2,8\% em 2012, num crescimento de 75\%. O produto econômico do estado cresceu cinco vezes somente neste início de século - de R $\$ 26$ bilhões em 2000 para R\$ 133 bilhões em 2013 (IMB, 2014). Mas as preocupações ambientais não acompanharam este ritmo: as pesquisas sobre o tema no Estado se resumem a alguns trabalhos nos setores de mineração e agronegócios, como açúcar e álcool, soja, avicultura, suinocultura, frigoríficos (CARMO; GUIMARÃES, 2002; RODRIGUES, 2007; TRINDADE; CHAVES, 2008; GENUINO; MACHADO, 2013; ANDRADE, 2010; ENRIQUEZ, 2009). Os últimos dados da Confederação Nacional da Indústria, em sondagem 
sobre o meio ambiente realizada em 2010 (CNI, 2010), mostravam a região Centro-Oeste como aquela com o menor percentual de empresas que declararam adotar procedimentos gerenciais associados à gestão ambiental, $67,7 \%$, contra $74,5 \%$ da região Sul, que apresentou a maior proporção.

Justifica-se, portanto, um estudo que acrescente àqueles já feitos informações acerca de como lidar na prática com os desafios da produção industrial com mínimo impacto ao meio ambiente.

\section{GESTÃO AMBIENTAL - CONTEXTO, CONCEITOS E MODELOS}

A insustentabilidade dos padrões atuais de consumo, o que inclui dispor de uma variada gama de produtos e serviços para uma vida confortável, já foi atestada por estudiosos como Furtado (1973) e North (1997). Setodos os povos da terra atingissem o nível de desenvolvimento econômico dos países ricos, os recursos não renováveis e a poluição do meio ambiente seriam de tal ordem que o sistema econômico mundial entraria em colapso. Conforme Ger (1999), a visão dominante da "boa vida" e suas respectivas exigências de consumo têm alto impacto em termos de meio ambiente. Na medida em que as pessoas buscam intensamente consumir neste contexto de vida confortável, a degradação ambiental e suas consequências se tornam uma realidade.

Há críticas sobre quem deveria assumir a responsabilidade por esses danos, mas é inegável que as empresas teriam boa parte da culpa. Barbieri (2011, p.2) coloca a questão desta forma: "Qualquer solução efetiva para os problemas ambientais terá necessariamente que envolver empresas, pois são elas que produzem e comercializam a maioria dos bens e serviços colocados à disposição da sociedade em praticamente todos os cantos do Planeta.”.

Um conceito fundamental para o entendimento da participação empresarial na prevenção ambiental é o Sistema de Gestão Ambiental (SGA), que Barbieri (2011) define como atividades administrativas e operacionais realizadas pela organização para lidar com problemas ambientais. Essas atividades podem buscar sanar problemas já decorrentes de sua atuação ou, ainda, de preferência, proativamente, evitar a ocorrência desses problemas no futuro. Neste estudo, esse conceito será abordado com enfoque empresarial, dentro da linha apresentada por Barbieri (2011) e Shigunov Neto et al. (2009), definido como um conjunto de políticas, programas e práticas administrativas e operacionais, visando à proteção do meio ambiente pela minimização de impactos e danos ambientais. 


\subsection{Modelos de Gestão Ambiental}

O caminho para uma boa gestão ambiental, incluindo diretrizes e princípios, foi estabelecido por diversas entidades internacionais. Uma série de modelos voluntários foi proposta, visando contribuir para que as atividades sistemáticas de preservação do meio ambiente nas organizações ocorressem da melhor forma possível. As siglas e nomes são muitos, mas em resumo, os principais modelos seguem abaixo relacionados, com base em Barbieri (2011), Shigunov et al. (2009), Seiffert (2010) e Oliveira e Machado (2009):

a) Responsible Care (Atuação Responsável): programa voluntário criado pela Associação Canadense da Indústria Química, nos anos 80, visando estabelecer princípios de atuação ambientalmente responsável para a indústria química, setor bastante associado com problemas e eventos nocivos ao meio ambiente. No Brasil, a Atuação Responsável está a cargo da ABIQUIM, Associação Brasileira da Indústria Química.

b) Modelo Winter - Sistema Integrado de Gestão Ambiental: modelo voluntário de gestão ambiental desenvolvido por George Winter em 1989, na Alemanha. As empresas perceberam que atuar de forma ambientalmente responsável significava uma vantagem competitiva. Daí, desenvolveram seus sistemas de gestão em consonância com a causa ambiental.

c) CERES (Coalision for Environmentally Responsible Economies): organização sem fins lucrativos criada para encorajar as empresas a desenvolverem programas que visam prevenir a degradação ambiental. O programa lançou uma série de princípios, visando a proteção ambiental, logo após o acidente no Alaska com o Exxon Valdez, em 1989.

d) STEP (Strategies for Today's Enviromental Partnership): programa criado em 1990 pelo American Petroleum Institute, visando desenvolver um guia para que a indústria de petróleo americana aprimorasse seu desempenho ambiental, de segurança e de saúde. Os princípios envolvem a prevenção da poluição, conservação de recursos naturais, parcerias com as comunidades, dentre outros.

e) EMAS (Eco-Management and Audit Scheme) - Sistema Europeu de Eco-Gestão e Auditorias: sistema estabelecido pelo regulamento 1836/93 da Comissão da Comunidade Européia - estabeleceu os critérios para certificações ambientais de processos industriais. Posteriormente, foram acrescentados a esses critérios um sistema de gestão de auditorias.

REAd | Porto Alegre - Edição 86 - No 2 - Maio / Agosto 2017 - p. 110 - 134 
f) Norma Britânica BS 7750: norma criada em 1992 pelo Instituto Britânico de Normalização; desenvolveu um documento que serviu de base à gestão ambiental, exigindo que as organizações formulem políticas e estabeleçam objetivos no trato com o meio ambiente.

g) Produção Mais Limpa (P+L): suportado pelo Programa das Nações Unidas para o Meio Ambiente - trata-se de uma abordagem de gestão ambiental preventiva de maneira integrada aos processos, produtos e serviços, visando melhorar a eficiência ecológica da empresa. Uma boa utilização deste modelo implica menos investimentos end-of-pipe (medidas corretivas) e mais ecoeficiência. As tecnologias limpas, que se baseiam no conceito de máxima produtividade de recursos e energia com mínimo descarte (SOKOLOVIC et al, 2012), encontram-se na ordem do dia das preocupações ambientais na Europa (DOGANOVA; KARNOE, 2015); desde 1996, a regulamentação da Comunidade Européia (DIRECTIVE, 2010/75/EU) tem pressionado as empresas industriais para que utilizem as melhores técnicas disponíveis de proteção ao meio ambiente.

h) ISO 14000 - Normas Internacionais para Gestão Ambiental: padrão voluntário, criado no início da década de 1990, pela International Organization for Standardization, com sede na Suíça, tem como objetivo proporcionar às organizações ferramentas para um sistema de gestão ambiental eficaz, com possibilidades de integração com outros sistemas de gestão, permitindo que se alcancem objetivos ambientais e econômicos. Baseia-se no ciclo PDCA, partindo de políticas ambientais, planejamento, implementação e operação, verificação e análise pela administração (BARBIERI, 2011).

De todos os modelos apresentados, o mais conhecido é a série ISO 14.000. Para obter a certificação, a empresa deve instituir e documentar um Sistema de Gestão Ambiental conforme os requisitos descritos na seção 4 da ISO 14.001. Assim como a certificação ISO para qualidade (série 9000), a certificação ISO na área ambiental confere à empresa detentora excelente reputação naquele quesito junto à comunidade empresarial, facilitando o relacionamento ao longo da cadeia produtiva e abrindo portas para negócios tanto no país, como principalmente no exterior.

\subsection{A Legislação e as Motivações para a Gestão Ambiental}


A legislação sobre meio ambiente pode assumir um papel que vai muito além de obrigar empresas e agentes econômicos a respeitar e preservar a natureza. Porter e Van der Linde (1995) argumentaram há duas décadas que uma legislação rigorosa tem o poder de fazer com que as empresas se antecipem em relação aos problemas ambientais. Uma legislação restrita retira produtos perigosos de circulação e reduz o uso de produtos nocivos como solventes e metais pesados. Segundo aqueles autores, a gestão ambiental deveria ser vista como um fator de competitividade e não como ameaças aos custos.

Sanches (2000) apresenta exemplos internacionais de empresas como 3M e Du Pont que foram forçadas a inovar criando insumos e produtos menos nocivos à natureza como resultado de legislações rigorosas sobre meio ambiente. Alperstedt e outros (2010) apresentam estudo em Santa Catarina, com empresas industriais, que revelou serem os fatores externos aqueles de maior peso nas motivações para a gestão ambiental foram pressões da sociedade e da legislação. Também corrobora este resultado o trabalho conduzido por Berardi e Barbieri (2013) em empresas industriais nos estados do Rio de Janeiro e Rio Grande do Sul, revelando baixo grau de maturidade das empresas pesquisadas, sendo evidente a legislação como fator de maior influência na gestão ambiental.

No Brasil, um dos marcos mais importantes da legislação foi a instituição da Política Nacional do Meio Ambiente (PNMA), por meio da Lei no 6938 de 1981, cujo objetivo é assegurar ao país desenvolvimento socioeconômico que preserve a qualidade ambiental propícia à vida. Seifert (2010) menciona que esta lei delimitou uma mudança de paradigma, já que no período anterior a ela a abordagem da política ambiental subordinava a questão da proteção ambiental ao desenvolvimento econômico. A partir da referida lei, passou a haver mais equilíbrio entre meio ambiente e desenvolvimento econômico,e a qualidade ambiental tornou-se um fator de grande importância para a qualidade de vida da população. Merecem destaque em relação à Lei6938, os princípios norteadores: (1) princípio do desenvolvimento sustentável desenvolvimento sem comprometer futuras gerações; (2) princípio do poluidor-pagador quem polui arca com o custo de prevenção; (3) princípio da preservação - incentivar mentalidade de prevenção; (4) princípio da participação - ação conjunta de todos os agentes sociais, econômicos e de governo e (5) princípio da ubiquidade - presença em todos os níveis da sociedade.

Outros instrumentos legais a serem destacados na área ambiental são: a Lei 9433, de 1997, que instituiu a Política Nacional de Recursos Hídricos, cujo objetivo é garantir às gerações atual e futura a disponibilidade de água em adequados padrões de qualidade; a Lei 12305, de 2010, que deu origem à Política Nacional de Resíduos Sólidos, que dispõe sobre a gestão 
integrada de resíduos sólidos, inclusive os perigosos, prevendo as responsabilidades de empresas e poder público, além dos instrumentos econômicos aplicáveis; e a Lei 9605, de 1998, a chamada Lei dos Crimes Ambientais, que prevê sanções penais e administrativas a partir de condutas e atividades que prejudiquem o meio ambiente.

A incorporação da questão ambiental na gestão estratégica das empresas já é uma realidade há mais de três décadas.Essa incorporação, segundo Cunha et al. (2009), tem ocorrido principalmente devido às pressões de diferentes stakeholders, com destaque para exigências de clientes, consumidores, concorrentes, sociedade e legislação. Ou seja, as motivações para a adoção de um sistema de gestão ambiental são muitas, mas as pesquisas mostram que a legislação é um dos principais incentivos.

\subsection{Maturidade da Gestão Ambiental}

Os modelos de maturidade de um modo geral trabalham com etapas evolutivas que costumam ir de um momento inicial, de pouca experiência e baixa familiaridade até os estágios mais avançados nos quais há domínio e possível liderança em relação a uma determinada técnica. Dentro desta lógica, os modelos de maturidade em gestão ambiental também se referem a fases pelas quais as empresas passam desde que se iniciam nesta atividade administrativa.

Neste estudo, a maturidade em gestão ambiental é abordada, conforme Seifert (2010), que apresenta três posturasdo tema por parte das organizações: passiva, reativa e proativa. $\mathrm{Na}$ abordagem passiva, a organização tem uma atitude negativa em relação às questões ambientais, considerando as mesmas como foco de redução de lucros; nestes casos, não há investimentos em controles de conformidade e a organização é alvo constante da fiscalização, ficando sujeita a multas e penalidades legais. Na abordagem reativa, a organização busca cumprir a legislação naquilo que for obrigatório; esta abordagem é conhecida também como end of pipe, ou seja, as medidas tomadas preocupam-se em tornar inertes ao meio ambiente os dejetos e efluentes decorrentes da área de operação; na abordagem proativa, a preocupação com o meio ambiente é incorporada desde o planejamento das atividades operacionais, o que garante boas práticas ao longo de todo o processo produtivo; nestes casos, não é incomum que as regras da organização sejam até mais severas que aquelas estabelecidas pela própria legislação.

Há outras terminologias utilizadas para indicar a evolução da maturidade na gestão ambiental. Walton e Handfield (1998) apresentam os seguintes estágios, em ordem de evolução: adaptação resistente, soluções end-of-pipe e vantagem competitiva. Hunt e Auster (1990)

REAd | Porto Alegre - Edição 86 - Nº 2 - Maio / Agosto 2017 - p. 110 - 134 
mencionam cinco estágios de evolução: begginer, fire fighter, end-of-pipe solutions e competitive advantage. Em ambos os casos, parte-se de uma situação de resistência, passando por etapas de reação, adaptação e finalmente proatividade na gestão ambiental. Jabbour e Santos (2006) também sistematizaram taxonomias evolutivas importantes em relação ao tema. Da mesma forma, autores como Hynds et al. (2014), Golinska e Kuebler (2014) e Okongwu et al. (2013), apresentam modelos em gestão ambiental de forma evolutiva, saindo de um estágio incipiente até chegar à maturidade propriamente dita.

A maturidade em relação à questão ambientaldepende do quanto a organização evoluiu nos diversos aspectos gerenciais desde que começou a lidar com o assunto. Sanches (2000), em estudo sobre melhores práticas, apresenta uma boa síntese sobre o tema. Empresas proativas incorporam fatores ambientais nas metas, políticas e estratégias, levando em conta riscos e impactos ambientais, tanto em relação ao processo produtivo quanto de seus produtos. O meio ambiente deixa de ser visto como um item de custo e se torna uma possibilidade de lucro, passando a ser considerado como base de negócios ou desenvolvimento de ideias. A abordagem proativa envolve o gerenciamento de riscos, ou seja, a identificação de danos potenciais e seleção de prioridades para alocação de recursos, a prevenção da poluição (minimização ou eliminação), e comunicação, traduzida como o compartilhamento dos ganhos do sucesso ambiental com os públicos de interesse. Ao atingir o estágio proativo, ganha corpo uma mudança de mentalidade na empresa. Por exemplo, pode haver alteração na postura em relação aos materiais reciclados, que no passado eram vistos como de baixa qualidade.

A proatividade requer espaço organizacional, conforme complementa Sanches (2000, p.81): “[...] ]as empresas industriais que buscam a proteção ambiental vêm incorporando uma nova função administrativa em sua estrutura, com um corpo técnico específico e um sistema gerencial especializado.”. Ou seja, há necessidade de criação de uma estrutura dedicada à gestão ambiental. Além disso, deve haver também uma boa conexão entre a função ambiental e os níveis administrativos mais altos, o que significa maior participação no planejamento estratégico da empresa.

A maturidade ambiental está ligada também à capacidade de articulação da empresa com os diversos públicos de interesse da mesma. Para Hart (1997), uma estratégia ambiental clara e integrada deveria modelar o relacionamento da empresa com consumidores, fornecedores, legisladores e todos os públicos de interesse. Dyllick e Hockerts (2002) acrescentam que empresas sustentáveis são capazes de desenvolver relacionamento de alto nível com as comunidades, agregando valor a estas.

REAd | Porto Alegre - Edição 86 - No 2 - Maio / Agosto 2017 - p. 110 - 134 


\section{GESTÃO AMBIENTAL E SEUS DESAFIOS EM GOIÁS}

Assim como outros estados do Centro-Oeste, Goiás abriga atividades econômicas com potencial considerável de agressividade ao meio ambiente. Embora não representem maior peso em produto econômico (IMB, 2014), atividades arroladas como de alto impacto (Manual de Impactos Ambientais, disponível em Dias (1999), estão presentes em todo o estado, como é o caso da agroindústria, envolvendo a produção de grãos (soja, milho, sorgo), cana de açúcar (açúcar e álcool), criação e abate de animais, frigoríficos, indústria extrativista (mineração), dentre outras.

Ao tempo em que o Brasil central passou a experimentar uma verdadeira revolução verde, com o crescente aumento da produtividade por hectare, começaram os problemas ambientais, principalmente por conta dos compostos nitrogenados que fazem parte dos fertilizantes utilizados na correção do solo do cerrado. Os compostos nitrogenados têm considerável potencial para poluir lençóis freáticos, abundantes na região. O avanço indiscriminado da agricultura de grãos, além de potencializar a poluição dos lençóis subterrâneos conforme mencionado, ainda ameaça os mananciais que contribuem para as principais bacias hidrográficas da América do Sul.

Em termos de gestão ambiental, algumas reações já se mostraram presentes no agronegócio, visando superar os problemas decorrentes do avanço da área cultivada sobre o cerrado. Técnicas como o sistema de plantio direto, que por manter o solo sempre coberto com plantas e resíduos vegetais, evita erosão e mantém os nutrientes necessários às culturas, além de reduzir a necessidade de uso de agroquímicos. Outra técnica que merece destaque é o controle biológico de pragas, que segundo Pallini $(2009$, p.1) é a “[...] redução das populações de determinado inseto-praga por meio da introdução no ambiente de seus inimigos naturais (insetos, pássaros, ácaros, vírus, etc.)”. A grande vantagem do controle biológico de pragas e do plantio direto é que o seu uso pode reduzir o consumo dos fertilizantes químicos que contaminam solo e água, e que são prejudiciais a organismos benéficos como predadores, abelhas e outros polinizadores.

Na seara da criação e abate de animais, a produção de suínos e aves na região de Rio Verde (GO) tem contribuído sobremaneira para o desenvolvimento econômico da região sudoeste de Goiás. Carmo e Guimarães (2002) apontam o surgimento de um verdadeiro polo de produção agropecuária com investimentos em tecnologia, tendo a participação de expressivas empresas como Embrapa, Cooperativa Comigo, instituições locais de pesquisa e ensino, além de 
transnacionais como Aventis, Basf, DuPont, Monsanto e Pioneer. No entanto, negócios com aves e suínos trazem a ocupação das terras por monocultura de soja e milho, que exigem uso pesado de agrotóxicos para correção dos solos, instalações de gigantescas granjas produtoras com os decorrentes custos ambientais referentes à erosão, contaminação da água por resíduos dos animais, redução da biodiversidade, dentre outros. A gestão ambiental na área de suínos e aves tem se utilizado de tecnologias como biodigestores que, além de evitar a poluição de rios e nascentes, tem como subprodutos a geração de energia e a produção de biofertilizantes, o que melhora a rentabilidade deste tipo de negócio (KONZEN, 2006; XAVIER et al., 2013).

$\mathrm{Na}$ área de frigoríficos, o estudo de Rodrigues (2007),em Goiás, mostrou que a maioria das empresas age de forma reativa, buscando apenas cumprir a legislação. Dois investimentos importantes para a gestão ambiental do setor são as lagoas de decantação para tratamento de dejetos e a rastreabilidade bovina. Quanto às lagoas de decantação, 100\% das empresas as possuem porque se trata de uma pré-condição para obtenção da licença ambiental. Já em relação à rastreabilidade, por não ser obrigatória, somente $24 \%$ dos frigoríficos o fazem. Esta prática é importante para trazer informações sobre tipo de corte, validade, sexo, idade, data do abate, temperatura de conservação, dentre outras.

Dos 25 frigoríficos investigados, apenas um possuía um Sistema de Gestão Ambiental; 80\% tinha comportamento reativo. $O$ fato de ter um SGA indica que a gestão ambiental na empresa é planejada e organizada para que toda a sua operação leve em conta o impacto no meio ambiente e o uso eficiente de recursos naturais. Uma motivação para a adoção de postura proativa é o fato de o frigorífico atender ao mercado externo. É notório que os frigoríficos que tem clientes internacionais apresentam postura em relação ao meio ambiente bastante diferenciada daqueles que só atendem ao mercado doméstico.

No setor sucroalcooleiro, os problemas ambientais não são poucos e estão ligados tanto a questões sociais quanto ambientais. Trindade e Chaves (2008) argumentam que, por estar ligado à monocultura, gera uma série de passivos ambientais. Sua presença tende a reduzir a biodiversidade transformando antigas áreas florestais em "florestas de cana-de-açucar", debilitando a fauna silvestre. Em termos de gestão ambiental, merece destaque a criação do Zoneamento Econômico Ecológico (áreas delimitadas nas quais os recursos naturais são utilizados de forma sustentável) das destilarias, além do uso dos licenciamentos e certificações ambiental.

Há de se ressaltar a pesquisa de Genuino e Machado (2013), realizada em nível nacional no setor sucroalcooleiro, que identificou a maioria das empresas pesquisadas em nível preventivo-avançado em termos de gestão ambiental. As práticas mais usuais apontadas pelos

REAd | Porto Alegre - Edição 86 - No 2 - Maio / Agosto 2017 - p. 110 - 134 
pesquisadores estavam ligadas ao controle de substâncias tóxicas e uso de biofertilizantes. Estes achados indicam evolução do setor na preservação ambiental e se contrapõem ao que Trindade e Chaves (2008) encontraram alguns anos antes em pesquisa em Goiás. Também Andrade (2010) relatou boa atuação em gestão ambiental no setor sucroalcooleiro sobre green supply chain neste estado.

Outra atividade econômica considerada agressiva ao meio ambiente e comum no CentroOeste é a mineração. Penna (2009) relata alguns dos motivos que corroboram esta afirmação: alto consumo de água nas diversas fases da exploração; derrame de óleos, graxas e metais pesados na natureza; redução de oxigênio dissolvido nos ecossistemas aquáticos; assoreamento de rios e poluição do ar por material particulado.

No entanto, Enriquez (2009), que conduziu pesquisa em vários municípios brasileiros nos quais ocorre a atividade de mineração, chegou a conclusões interessantes: municípios que mantém base mineradora têm um forte sistema de proteção ambiental. Um maior grau de maturidade da gestão ambiental foi identificado nas mineradoras mais novas, que incorporam padrões internacionais. As mineradoras recentes, construídas sob legislação mais rigorosa, apresentam estrutura de gestão ambiental bem mais desenvolvida que as mineradoras antigas (presentes no Sudeste do Brasil), inauguradas numa época em que as consequências ambientais da atividade mineradora ainda não eramestritamente monitoradas. Esta constatação vem ao encontro do argumento de Porter e Van der Linde (1995) para os quais uma legislação rigorosa tem o poder de incentivar a inovação e produzir uma gestão ambiental mais eficiente, com menor consumo de recursos naturais e energia.

Enriquez (2009) constata também que mineradoras que destinam suas vendas ao exterior têm melhor performance quando comparadas com seus pares que vendem somente ao mercado doméstico. Repete-se novamente o mesmo padrão encontrado nos frigoríficos, ou seja, empresas que lidam com clientes de exportação, mais exigentes, precisam se adequar aos padrões internacionais mais rígidos da gestão ambiental.

\section{MÉTODO}

Para avaliar as melhores práticas em gestão ambiental, optou-se pelo estudo de casos múltiplos em três empresas no estado de Goiás. A justificativa para escolher as empresas foi que as mesmas tivessem sistemas de gestão ambiental bem estruturados e que realizassem um trabalho nesta área que pudesse servir de referência. Ou seja, o pré-requisito para a escolha das empresas era que as mesmas estivessem utilizando as melhores práticas em gestão 
ambiental. Por não haver ranking disponível sobre as organizações que mais se destacavam neste assunto, optou-se por trabalhar com empresas que tivessem a certificação ISO 14001. O estudo de caso como método de pesquisa encontra fortes argumentos no trabalho de Yin (2005). Na impossibilidade de se manipular comportamentos, como nos experimentos clássicos, o pesquisador tem condições de entender os porquês de um determinado fenômeno por meio da observação direta, do contato com pessoas envolvidas, pelo acesso a documentos e objetos relacionados a este fenômeno. Sobre a quantidade de casos utilizados, o próprio Yin recomenda que seja dada preferência, sempre que possível, a casos múltiplos ao invés de únicos como forma de aumentar a validade externa das descobertas.

Houve dificuldades neste sentido. Em geral, percebeu-se que as empresas não se mostraram predispostas a abrir as portas para falar sobre o assunto gestão ambiental. É compreensível isso, uma vez que o tema envolve questões delicadas, como a relação da organização com o meio ambiente, com as comunidades e com as esferas de governo. Além disso, a gestão ambiental é bastante regulamentada e o não cumprimento da legislação pode resultar em pesadas multas aos infratores, o que aumenta ainda mais a desconfiança em relação a qualquer interessado em abordar o assunto. Dado todo o receio de tratar abertamente a questão, aquelas organizações que prontamente aceitaram o desafio de receber o pesquisador e autor deste artigo para falar sobre o assunto, sem quaisquer restrições ou exigências, já sinalizaram estar bem resolvidas em relação ao tema. Fura (2013) também identificou dificuldades em obter colaboração de algumas empresas, atribuindo as recusas a possíveis não conformidades em relação às regulamentações. As organizações que se prontificaram a colaborar foram aquelas adotantes da ISO 14001, já acostumadas a abrir ao público suas informações sobre meio ambiente.

Foram abordadas seis empresas: três concordaram em participar, a saber: a Mineração AngloAmerican, situada em Barro Alto (GO), a Refrescos Bandeirantes, franqueada da Coca Cola Brasil, em Trindade (GO) e a Usina Jalles Machado, no município de Goianésia (GO).

Trata-se de uma amostra obtida por conveniência, uma vez que somente três empresas foram escolhidas de todo o universo de organizações certificadas em Goiás. Uma maneira objetiva de viabilizar as escolhas foi que estas organizações tivessem certificação ISO 14001 há mais de 5 (cinco) anos.

\subsection{Protocolo do Estudo de Caso}


O protocolo utilizado neste estudo de casos múltiplos tem roteiro que inclui procedimentos de campo, modelo de análise e roteiro de questões e apresentação dos resultados.

\subsection{Procedimentos de Campo}

Para ser consistente com os objetivos do trabalho, as três empresas foram escolhidas tendo como critério básico que estivessem bastante evoluídas em termos de gestão ambiental. As empresas AngloAmerican, Refrescos Bandeirantes e Usina Jalles Machado foram visitadas pessoalmente por um dos pesquisadores autores deste artigo. Durante as visitas foram entrevistados os profissionais responsáveis pela área de gestão ambiental, sendo que os cargos dos respondentes eram de gerentes, supervisores e analistas. Além das entrevistas, houve visita às instalações, sendo percorridas as áreasoperacionais das empresas. Complementando as informações referentes aos casos, houve acesso a documentos, relatórios e folhetos explicativos sobre a gestão ambiental na empresa por meios impressos e digitais. As três organizações foram visitadas entre 2012 e 2014 e, posteriormente, foram mantidos contatos com as pessoas envolvidas de modo que fosse dada continuidade às investigações.

\subsection{Modelo de Análise e Roteiro de Questões}

O roteiro do estudo de caso, utilizado nas entrevistas, teve por base a literatura de gestão ambiental apresentada na fase inicial do artigo. Tomando os temas mais críticos sobre o assunto, foi elaborado o modelo de análise estruturado no Quadro 1.

Quadro 1 - Gestão Ambiental - Modelo de Análise

\begin{tabular}{|l|l|l|}
\hline \multicolumn{1}{|c|}{ Temas para o roteiro } & \multicolumn{1}{|c|}{ Abordagens } & \multicolumn{1}{c|}{ Autores } \\
\hline \multirow{4}{*}{$\begin{array}{l}\text { Motivos para adotar um sistema } \\
\text { de gestão ambiental }\end{array}$} & $\begin{array}{l}\text { insustentabilidade dos padrões } \\
\text { atuais de consumo }\end{array}$ & North (1997) \\
\cline { 2 - 3 } & visão dominante da "boa vida" & Ger (1999) \\
\cline { 2 - 3 } & legislação rigorosa & $\begin{array}{l}\text { Porter e Van der Linde (1995); } \\
\text { Seiffert (2010); Sanches (2000); } \\
\text { Berardi e Barbieri (2013) }\end{array}$ \\
\cline { 2 - 3 } Modelos e instrumentos de & padrões internacionais & Enriquez (2009) \\
\cline { 2 - 3 } gestão ambiental & pressão da sociedade & Alperstedt e outros (2010) \\
\hline & sistema de Gestão ambiental & Barbieri (2011) \\
\cline { 2 - 3 } & $\begin{array}{l}\text { políticas, programas e práticas } \\
\text { administrativas }\end{array}$ & Shigunov Neto et al. (2009) \\
\hline
\end{tabular}




\begin{tabular}{|c|c|c|}
\hline & $\begin{array}{l}\text { principais modelos de Gestão } \\
\text { Ambiental }\end{array}$ & $\begin{array}{l}\text { Barbieri (2011); Shigunov Neto } \\
\text { et al. (2009); Seiffert (2010); } \\
\text { Oliveira e Machado (2009) }\end{array}$ \\
\hline $\begin{array}{l}\text { Estrutura organizacional que dê } \\
\text { suporte à gestão ambiental }\end{array}$ & $\begin{array}{l}\text { incorporação da função na } \\
\text { estrutura organizacional }\end{array}$ & Sanches (2000) \\
\hline \multirow{2}{*}{$\begin{array}{l}\text { Planejamento e a gestão } \\
\text { ambiental }\end{array}$} & pressão de stakeholders & Cunha et al. (2009) \\
\hline & $\begin{array}{l}\text { estratégia ambiental clara e } \\
\text { integrada }\end{array}$ & Hart (1997) \\
\hline $\begin{array}{l}\text { Investimentos na área de gestão } \\
\text { ambiental }\end{array}$ & $\begin{array}{l}\text { incorporados à operação; } \\
\text { desperdício zero - Produção + } \\
\text { limpa: mais eficiência, menos } \\
\text { desembolsos end-of-pipe }\end{array}$ & $\begin{array}{l}\text { Barbieri (2011), Oliveira e } \\
\text { Machado (2009) }\end{array}$ \\
\hline $\begin{array}{l}\text { Relacionamento da empresa com } \\
\text { a comunidade local }\end{array}$ & $\begin{array}{l}\text { agregação de valor a } \\
\text { comunidades }\end{array}$ & Dyllick e Hockerts (2002) \\
\hline \multirow{4}{*}{$\begin{array}{l}\text { Maturidade da gestão ambiental } \\
\text { na empresa }\end{array}$} & $\begin{array}{l}\text { posturas: passiva, reativa e } \\
\text { proativa }\end{array}$ & Seiffert (2010) \\
\hline & estágios de evolução & $\begin{array}{l}\text { Walton e Handfield (1998); Hunt } \\
\text { e Auster (1990); Hynds et al. } \\
\text { (2014); Golinska e Kuebler } \\
\text { (2014); Okongwu et al.(2013) }\end{array}$ \\
\hline & taxonomias evolutivas & $\begin{array}{l}\text { Jabbour e Santos (2006), Seifert } \\
(2010)\end{array}$ \\
\hline & melhores práticas & Sanches $(2000)$ \\
\hline
\end{tabular}

Fonte: Autores

\section{APRESENTAÇÃO DOS RESULTADOS}

A apresentação dos resultados é feita em duas etapas: (1) apresentação das três empresas de forma individual e (2) análise dos temas referentes aos modelos e práticas de gestão ambiental de maneira conjunta.

\subsection{Empresas Participantes do Estudo De Caso}

Conforme já informado, as empresas participantes do estudo de caso são Anglo American Brasil (mineração), Refrescos Bandeirantes (indústria de bebidas) e Usina Jalles Machado (setor sucroalcooleiro).

\subsubsection{Anglo American Brasil}

A Anglo American iniciou suas operações em 1917, na África do Sul, com exploração de minas. Hoje, está presente em cinco continentes, em países como Austrália, India, China, Canadá. Na América do Sul atua no Chile, Peru Colômbia, Venezuela e Brasil, onde tem três 
negócios principais: níquel em Goiás desde 1979, minério de ferro em Minas Gerais desde 2008 e fosfato e nióbio, também em Goiás, desde os anos de 1950. Os investimentos feitos no Brasil somam US\$ 14 bilhões desde 2007, com destaque para o projeto Minas-Rio, de US\$ 5 bilhões. A planta de Barro Alto (unidade objeto deste estudo) emprega 560 colaboradores e custou US\$ 1,9 bilhão aos acionistas do grupo. O Brasil é um país no qual a Anglo American tem seus maiores investimentos.

\subsubsection{Refrescos Bandeirantes}

A Refrescos Bandeirantes, criada em 1986, está localizada no município de Trindade, GO (centro produtor), emprega 2.600 colaboradores diretos e 5.200 colaboradores indiretos. Com estrutura de 10 centros de distribuição, atende a 237 cidades nos estados de Goiás e Tocantins, que agregam 29.000 pontos de venda. É líder na região nos segmentos de refrigerantes, águas, chás e sucos e vice-líder nas cervejas e isotônicos.

\subsubsection{Usina Jalles Machado S/A}

A Usina Jalles Machado foi criada em 1983, por iniciativa da família Lage de Siqueira, na cidade de Goianésia (GO), tendo como contexto econômico os incentivos fiscais oferecidos na época pelo governo federal aos participantes do programa Proálcool. Foi uma das primeiras usinas a utilizar o bagaço de cana para cogeração de energia; dados de 2014 mostram que a empresa conta com uma força de trabalho de 2.600 colaboradores. Investiu desde o início de suas atividades na produção orgânica; atualmente produz etanol anidro e hidratado, açúcar, produtos de higiene e limpeza, energia elétrica, levedura e látex. A Empresa possui várias certificações e exporta para Europa, Japão, Estados Unidos, Canadá e Comunidade Judaica.

\subsection{Gestão Ambiental - Modelos e Práticas nas Empresas em Estudo}

O quadro 2 apresenta um roteiro dos itens abordados no estudo de casos múltiplos. A abordagem utilizada começou com um breve histórico sobre a gestão ambiental na empresa, passando pelos motivos para a implantação do SGA, modelos e ferramentas, estrutura organizacional, planejamento estratégico, relacionamento com a comunidade, investimentos na área e maturidade da gestão ambiental.

REAd | Porto Alegre - Edição 86 - No 2 - Maio / Agosto 2017 - p. 110 - 134 
Quadro 2 - Síntese dos Estudos de Caso

\begin{tabular}{|c|c|c|c|}
\hline & \multicolumn{3}{|c|}{ Empresas dos Estudo de Caso } \\
\hline Aspectos Abordados & $\begin{array}{l}\text { AngloAmerican } \\
\text { Barro Alto (GO) } \\
\text { (Mineração) }\end{array}$ & $\begin{array}{l}\text { Refrescos } \\
\text { Bandeirantes } \\
\text { Trindade (GO) } \\
\text { (Ind. Bebidas) } \\
\end{array}$ & $\begin{array}{l}\text { Jalles Machado } \\
\text { Goianésia (GO) } \\
\text { (Sucroalcooleiro) }\end{array}$ \\
\hline $\begin{array}{l}\text { Motivos para adotar um } \\
\text { sistema de gestão } \\
\text { ambiental }\end{array}$ & $\begin{array}{l}\text { Exigência a partir do } \\
\text { padrão mundial de } \\
\text { atuação da empresa }\end{array}$ & $\begin{array}{l}\text { Pressões para adoção } \\
\text { do SGA advindos da } \\
\text { atuação internacional da } \\
\text { Coca Cola Company }\end{array}$ & $\begin{array}{l}\text { Iniciativa da própria } \\
\text { direção da empresa, } \\
\text { com o } 1^{\circ} \text { projeto (Ame } \\
\text { a Ema), início anos } \\
1990\end{array}$ \\
\hline $\begin{array}{l}\text { Modelos e instrumentos } \\
\text { de gestão ambiental }\end{array}$ & $\begin{array}{l}\text { SGA com base no } \\
\text { padrão ISO } 14001 \text {, } \\
\text { implementado desde } \\
2001\end{array}$ & $\begin{array}{l}\text { Sistema de Gestão } \\
\text { Ambiental baseado na } \\
\text { ISO } 14001 \text { - } \\
\text { certificação em } 2008\end{array}$ & $\begin{array}{l}\text { SGA com base na ISO } \\
14001, \text { sendo a } \\
\text { certificação obtida em } \\
2004\end{array}$ \\
\hline $\begin{array}{l}\text { Estrutura } \\
\text { organizacional que dê } \\
\text { suporte à gestão } \\
\text { ambiental }\end{array}$ & $\begin{array}{l}\text { Equipe formada por } 1 \\
\text { gerente e três } \\
\text { engenheiros ambientais } \\
\text { - na unidade visitada }\end{array}$ & $\begin{array}{l}\text { Equipe formada por } \\
\text { dois gerentes, um } \\
\text { supervisor e um } \\
\text { analista; }\end{array}$ & $\begin{array}{l}\text { Equipe formada por } 1 \\
\text { gerente, três } \\
\text { engenheiros ambientais } \\
\text { e } 1 \text { analista de } \\
\text { qualidade }\end{array}$ \\
\hline $\begin{array}{l}\text { Planejamento e gestão } \\
\text { ambiental }\end{array}$ & $\begin{array}{l}\text { SGA faz parte de um } \\
\text { documento amplo, } \\
\text { "Nossos princípios de } \\
\text { negócios", que baliza } \\
\text { toda a atuação da } \\
\text { empresa }\end{array}$ & $\begin{array}{l}\text { SGA está inserido no } \\
\text { planejamento da } \\
\text { empresa em estudo, que } \\
\text { atua alinhada à The } \\
\text { Coca Cola Co., Atlanta, } \\
\text { EUA }\end{array}$ & $\begin{array}{l}\text { SGA é tido como área } \\
\text { estratégica na empresa. } \\
\text { Os cuidados com o } \\
\text { meio ambiente faz parte } \\
\text { das oportunidades de } \\
\text { negócio }\end{array}$ \\
\hline $\begin{array}{l}\text { Investimentos na área } \\
\text { de gestão ambiental }\end{array}$ & $\begin{array}{l}\text { Os investimentos estão } \\
\text { incorporados no } \\
\text { processo produtivo - } \\
\text { algumas rubricas } \\
\text { registram certos gastos } \\
\text { específicos, mas toda a } \\
\text { operação é voltada à } \\
\text { gestão ambiental }\end{array}$ & $\begin{array}{l}\text { Investimentos } \\
\text { incorporados ao } \\
\text { processo produtivo. É } \\
\text { possível identificar } \\
\text { somente os gastos } \\
\text { diretos com pessoal ou } \\
\text { alguns desembolsos } \\
\text { específicos com } \\
\text { equipamentos }\end{array}$ & $\begin{array}{l}\text { Investimentos } \\
\text { incorporados aos } \\
\text { processos produtivos. }\end{array}$ \\
\hline $\begin{array}{l}\text { Relacionamento da } \\
\text { empresa com a } \\
\text { comunidade local }\end{array}$ & $\begin{array}{l}\text { Participação ativa, } \\
\text { buscando envolvimento } \\
\text { com a comunidade e } \\
\text { instituições locais }\end{array}$ & $\begin{array}{l}\text { Empresa apoia diversas } \\
\text { iniciativas e programas } \\
\text { junto a cooperativas e } \\
\text { escolas }\end{array}$ & $\begin{array}{l}\text { A empresa envolve-se } \\
\text { em vários programas } \\
\text { comunitários, sendo o } \\
\text { do plantio de } \\
\text { seringueiras o mais } \\
\text { conhecido }\end{array}$ \\
\hline $\begin{array}{l}\text { Maturidade da gestão } \\
\text { ambiental na empresa }\end{array}$ & $\begin{array}{l}\text { Estágio proativo - SGA } \\
\text { incorporado ao } \\
\text { planejamento e } \\
\text { operação da empresa }\end{array}$ & $\begin{array}{l}\text { Estágio proativo - SGA } \\
\text { integrado à operação da } \\
\text { empresa }\end{array}$ & $\begin{array}{l}\text { Estágio proativo - SGA } \\
\text { faz parte do } \\
\text { planejamento e } \\
\text { processo operacionais } \\
\text { da empresa }\end{array}$ \\
\hline
\end{tabular}

Fonte: autores

Em termos históricos, as empresas estudadas se envolveram com o tema por tempo suficiente para a formação de uma boa curva de aprendizado com as práticas usuais. Na Anglo American, a estrutura de gerenciamento na área ambiental foi criada em 1995. O tema gestão ambiental, no Brasil, começou a ser discutido em 1992, na unidade Níquel (Niquelândia, GO). A empresa possui um padrão de governança que começa com os conceitos fundamentais de 
visão, princípios e políticas definidos para atuação internacional. De um modo geral, as diretrizes de gestão ambiental estão assentadas em proatividade e aprendizado; proatividade no sentido de se antecipar e planejar as atividades já incorporando boas práticas operacionais que consideram os reflexos no meio ambiente; e aprendizado na medida em que se busca aprender com os incidentes no dia-a-dia, evitando a repetição dos erros. A empresa tem a certificação ISO 14001 desde 2001.

$\mathrm{Na}$ área de gestão ambiental, a Refrescos Bandeirantes atua buscando melhorar a eficiência no consumo de recursos naturais - água e energia, desenvolver embalagens sustentáveis, reduzir as emissões de carbono, além de plano para recolher 100\% das embalagens colocadas no mercado até 2020. A atuação na gestão ambiental é balizada pelo padrão de qualidade oriundo da matriz da Coca-Cola em Atlanta, que segue a regulamentação norte-americana em relação a questões de meio ambiente, saúde e segurança. A unidade trabalha com documentação da matriz dos EUA. Desde 2008, a empresa é certificada pela ISO 14001. A utilização de latas de alumínio 100\% recicláveis começou no início dos anos de 1990, assim como as garrafas plásticas retornáveis. Em 2004, teve início nas fábricas da Coca-Cola o plano de aproveitamento de água da chuva.

A Jalles Machado obteve a certificação ISO 14001 em 2004, mas as iniciativas na área de gestão ambiental datam do início dos anos de 1990, quando foi criada a Comissão Interna de Meio Ambiente (CIMA), que desenvolveu uma série de ações como a adoção da coleta seletiva, o programa de recuperação de matas ciliares, a realização de campanhas ecológicas de um modo geral, envolvendo as comunidades locais naquela região do estado de Goiás (Goianésia, GO).

Nas três empresas estudadas, a gestão ambiental era um tema conhecido há pelo menos duas décadas; nessas organizações, as ações em prol do meio ambiente tiveram início na primeira metade dos anos de 1990. Este já é um aspecto de relevância a ser destacado: as certificações ISO 14001 vieram após alguns anos de familiaridade com o tema nos anos 2000 (2001 na Anglo American, 2008 na Refrescos Bandeirantes e 2004 na Jalles Machado). É possível identificar aqui um padrão no qual os anos iniciais serviramde aprendizado,até que finalmente uma ferramenta formal fosse adotada como base para a gestão ambiental. Ou seja, os casos mostraram a importância do fator tempo no processo de adoção de uma nova mentalidade de trabalho, mais especificamente, a gestão de negócios com tratamento sistemático dos impactos da atividade empresarial no meio ambiente.

Nos motivos que mais influenciaram a implantação do sistema de gestão ambiental figuram principalmente a atuação internacional das empresas como padrão de referência. No caso da 
Anglo American, o padrão de atuação mundial prevê procedimentos até mais rigorosos que as práticas consagradas como ISO 14.001 ou mesmo a legislação sobre o tema no pais. Na Refrescos Bandeirantes também a gestão ambiental é balizada pelo padrão de qualidade oriundo da matriz da Coca Cola em Atlanta (EUA), que segue a regulamentação norteamericana em relação a meio ambiente, saúde e segurança. Nestas duas empresas, o padrão internacional de atuação das sedes é o guia mestre da gestão ambiental. Na Jalles Machado não houve esse tipo de influência porque se trata de empresa brasileira, no entanto, pode-se afirmar que uma carteira de exigentes clientes internacionais colaborou bastante para o padrão de qualidade da gestão ambiental desta empresa.

Chama a atenção que o motivo de maior influência reportado pela literatura é a exigência da legislação sobre o meio ambiente. Entretanto, para as três empresas estudadas o principal motivo de adoção de um SGA foram outros que não a legislação: estas empresas se anteciparam à legislação. Mesmo Porter e Van der Linde (1995) tendo argumentado que uma legislação restritiva seja um grande incentivo à inovação na área do meio ambiente, ir além das exigências legais indica fortemente que o tema tem maturidade e é abordado de forma proativa na organização.

Sobre os modelos que servem de suporte à gestão ambiental, a série ISO 14.000 é o grande balizador. As três empresas mantém seus sistemas de gestão ambiental assentados sobre os fundamentos daquela padronização internacional. Um aspecto de destaque já mencionado é que os esforços de gestão ambiental tiveram início anos antes de as empresas obterem a certificação ISO - de seis a quinze anos nas empresas estudadas. Isso sinaliza que a adoção formal do referido padrão internacional ocorreu somente após as empresas terem adquirido mais maturidade em relação ao assunto.

Sobre a organização, um ponto que as três empresas têm em comum é a presença de uma estrutura formal no organograma. Isso quer dizer que há recursos humanos dedicados exclusivamente à gestão ambiental, o que garante a atenção suficiente para que o tema tenha bom encaminhamento. Apresença de uma estrutura formal, com reporte para as instâncias superiores, revela que as empresas reconhecem a importância do assunto para a organização, como também consideram que vale a pena investir em capacitação. Trata-se de um importante indicador de maturidade organizacional.

Com relação à gestão ambiental estar ou não inserida no planejamento empresarial, nos três casos avaliados, o tema encontra-se nas esferas estratégicas, e é conduzido pela alta direção das empresas. Em todas elas, o assunto prevenção ambiental é responsabilidade dos altos executivos e faz parte do planejamento de curto e longo prazo.

REAd | Porto Alegre - Edição 86 - No 2 - Maio / Agosto 2017 - p. 110 - 134 
O relacionamento das empresas em estudo com as comunidades locais é bastante rico e engloba uma série de atividades. As três empresas envolvem-se com prefeituras, escolas, creches e outras instituições visando promover programas educativos e comunitários na área de preservação do meio ambiente.

Sobre os investimentos em gestão ambiental, merece destaque o fato de que nas empresas estudadas, estes estão incorporados ao planejamento da operação, não sendo possível em muitas situações separar os gastos realizados especificamente com prevenção ambiental. É o caso de novos equipamentos que já incorporam em seus processos um menor consumo de energia, água e outros insumos - são as chamadas tecnologias limpas.

O último item de avaliação no quadro 2, maturidade em gestão ambiental, ocorre com base no conjunto dos itens anteriores: a experiência das organizações em estudo com o tema, a presença de uma estrutura de governança dedicada, a utilização de certificação internacional voluntária (ISO 14.000),o fato de a gestão ambiental fazer parte do planejamento estratégico, além de um relacionamento profícuo com as comunidades locais, este grupo de práticas arroladas autoriza a classificação das organizações em estágio proativo.Ou seja, nas três empresas objeto dos estudos de caso múltiplos, a gestão ambiental encontra-se em alto nível de maturidade.

Em síntese, a análise permitiu identificar uma série de aspectos que são comuns a empresas com maturidade em gestão ambiental: (1) planejam a gestão ambiental antecipadamente, evitando lidar com o assunto de forma reativa, somente na medida em que os problemas surgem;(2) antecipam-se às exigências da legislação, procurando adotar os procedimentos mais atualizados em relação ao tema; (3) adotam ferramenta de gestão ambiental de padrão internacional, no caso a ISO 14001, lembrando que este não é um instrumento de uso obrigatório previsto em legislação; (4) possuem equipes formais dedicadas à gestão ambiental, indicando que investem em pessoal qualificado para lidar com o assunto; (5) investem de maneira planejada, incorporando a gestão ambiental ao processo produtivo, evitando situações reativas em que se instalam equipamentos antipoluição apenas ao final do processo (end-of-pipe); (6) revelam maturidade no relacionamento com as comunidades e governos locais, envolvendo-se em diversos programas de educação e prevenção ambiental junto às escolas, cooperativas e outras entidades locais.

\section{CONSIDERAÇÕES FINAIS}

REAd | Porto Alegre - Edição 86 - No 2 - Maio / Agosto 2017 - p. 110 - 134 
Visando evidenciar os esforços de gestão na área ambiental empresarial, este estudo teve por objetivo fazer uma avaliação das melhores práticas em organizações que se encontram em estágio de alta maturidade no assunto.

A pesquisa foi realizada por meio de estudos de caso múltiplos em três empresas industriais que operam no Centro-Oeste, região na qual o tema preservação ambiental é bastante crítico. Os setores às quais pertencem as organizações são: sucroalcooleiro, alimentos e bebidas, e mineração.

Embora atuando em ramos de negócio diferentes, as organizações investigadas apresentaram vários pontos em comum em termos de gestão ambiental. Começando pela experiência no assunto; ficou claro que os anos iniciais de familiarização com as questões ambientais serviram de base para a adoção da certificação ISO 14.001, que é o guia orientador e padrão internacional das melhores práticas. De um modo geral, a legislação é o motivador mais forte para a adoção dos procedimentos de prevenção, mas nos casos estudados, as referências estavam além da regulamentação, e tomaram como base as exigências internacionais de stakeholders, como clientes e board executivo das matrizes no exterior. Também ficou evidente a necessidade de estruturar uma área com pessoas capacitadas a lidar de forma dedicada ao tema, e que esta estrutura esteja bem situada no organograma de modo a participar do planejamento e das decisões estratégicas da organização. Outro aspecto comum identificado nas empresas estudadas foi a atenção que elas dispensam às comunidades locais, participando de eventos e se envolvendo na resolução de problemas ambientais e sociais.

A combinação de todos estes elementos permite reconhecer que a maturidade em gestão ambiental advém de esforços múltiplos e organizados; uma prática isolada não caracteriza proatividade em relação ao tema.

\section{CONTRIBUIÇÕES E LIMITAÇÕES DO ESTUDO}

Embora a gestão ambiental já esteja na pauta das organizações há muitas décadas, e os modelos voluntários de melhores práticas, dentre eles o mais conhecido como a série ISO 14.000, já sejam conhecidos desde os anos 90, não são muitos os estudosque mostrem de maneira sistematizada como se constrói maturidade em gestão ambiental do ponto de vista empresarial, principalmente na região Centro-Oeste do Brasil,

Espera-se que os resultados apresentados possam servir de referência a outras organizações e que o assunto seja abordado e discutido de forma mais aberta pela comunidade acadêmica e empresarial.

REAd | Porto Alegre - Edição 86 - No 2 - Maio / Agosto 2017 - p. 110 - 134 
As limitações do estudo ficam por conta das restrições impostas pelo método escolhido, o estudo de casos, que não permite generalizações dos resultados alcançados; os achados são válidos apenas para as empresas estudadas.

\section{REFERÊNCIAS}

ALPERSTEDT, G.D.; QUINTELLA, R.H.; SOUZA, L.R. Estratégias de gestão ambiental e seus fatores determinantes: uma análise institucional. Revista RAE, São Paulo, v. 50, n. 2, abr./jun. 2010.

ANDRADE, M.C.F. Green SupplyChain e Sustentabilidade na Agroindústria Canavieira: o caso Jalles Machado S.A. Dissertação (Mestrado) - Universidade do Vale do Rio dos Sinos, 2010.

BARBIERI, J.C. Gestão Ambiental Empresarial: Conceitos, Modelos e Instrumentos. 3. ed. São Paulo: Saraiva, 2011.

BERARDI, P.C.; BARBIERI, J.C. Isomorfismos como motivadores da evolução da gestão ambiental: um estudo com médias e grandes empresas de dois estados brasileiros. In: ENCONTRO DA ANPAD, 37., Rio de Janeiro, 2013.Anais...Rio de Janeiro: ANPAD, set. 2013.

BRUNI, A. L. et al. Verde Que Te Quero Ver? Um Estudo Sobre Responsabilidade Social e Relações de Consumo. In: ENCONTRO DA ANPAD, 32., Rio de Janeiro, 2008. Anais...Rio de Janeiro: ANPAD, set. 2008.

BOWEN, H. R. Social responsabilities of the businessman. Iowa City: University of Iowa Press, 2013.

CARMO, R.L.; GUIMARÃES, E.; Azevedo, A. M. M. Agroindústria, população e ambiente no Sudoeste de Goiás. In: ENCONTRO DA ASSOCIAÇÃ O BRASILEIRA DE ESTUDOS POPULACIONAIS, 13., Ouro Preto, 2002.Anais... Ouro Preto, MG: ABEP, nov. 2002.

CNI - Confederação Nacional da Indústria. Sondagem Especial Meio Ambiente. Ano 8, n. 2, set. 2010.

CUNHA, J. et al. Modelos e tipologias de Gestão Ambiental: Subsídios para o estudo das mudanças nos processos de Adaptação Organizacional. In: ENCONTRO DA ANPAD, 33., São Paulo, 2009. Anais... São Paulo: ANPAD, set. 2009.

DIAS, M.C.O. Manual de impactos ambientais: orientações básicas sobre aspectos ambientais de atividades produtivas. Fortaleza: Banco do Nordeste, 1999. 297 p. Disponível em: <http://www.mma.gov.br/estruturas/sqa_pnla/_arquivos/manual_bnb.pdf >. Acesso em: dez.2014.

DOGANOVA, L.; KARNOE, P. Building markets for clean technologies: controversies, environmental concerns and economic worth. Industrial Marketing Management,Amsterdam, v. 44, jan. 2015. 
DIRECTIVE 2010/75/EU of the European Parliament and of the Council of 24 November 2010, on industrial emissions (integrated pollution prevention and control). Official Journal of the European Union, 17.12.2010.

DYLLICK, T.; HOCKERTS, K. Beyond the business case for corporate sustainability. Business Strategy and the Environment,Hoboken, v. 11, p.130-141,Mar./Apr. 2002.

EL-ANSARY, A.I. Societal marketing: A strategic view of the marketing mix in the 1970's. Academy of Marketing Science, [s.1.], Journal (pre-1986),v. 2, n. 4, Fall 1974.

ENRIQUEZ, M.A.R.S. Mineração e desenvolvimento sustentável - é possível conciliar? Revista de La Red Ibmeroamericana de Economia Ecológica, Rio de Janeiro, v. 12, p. 5166, 2009.

FURA, B. Improving ISO 14001 environmental management systems. Polish Journal of Environmental Studies, Olsztyn,v. 22, n. 6, 2013.

FURTADO, C. O mito do desenvolvimento econômico. Rio de Janeiro: Paz e Terra, 1973.

GENUINO, S.L.V.; MACHADO, A.G.C. Gestão ambiental no setor sucroalcooleiro brasileiro. In: ENCONTRO DA ANPAD, 37., Rio de Janeiro, 2013.Anais... Rio de Janeiro: ANPAD, set.2013.

GER, G. Consumption and Environmental Sustainability Across Cultures. Advances in Consumer Research, [s.1.], v. 26, 1999.

GOLINSKA, P.; KUEBLER, F. The method for assessment of the sustainability maturity in remanufacturing companies. In: CONFERENCE ON LIFE CYCLE ENGINEERING, 21., Trondheim, 2014.Proceedings... Trondheim: [s.n.], 2014.

HART, S.L. Beyond greening: strategies for a sustainable world. Harvard Business Review,Cambridge, v. 75, n. 1, jan./feb. 1997.

HYNDS, J.E. et al. A maturity model for sustainability in new product development. Research-Technology Management, Abingdon, jan./feb. 2014.

HUNT, C.B.; AUSTER, E.R. Proactive environmental management: avoiding the toxic trap. Sloan Management Review,Cambridge, v. 31, n. 2, Winter 1990.

IMB - INSTITUTO MAURO BORGES. Produto Interno Bruto do Estado de Goiás. Goiânia (GO), 2014. Disponível em:〈http://www.imb.go.gov.br/>. Acesso em: out. 2014.

JABBOUR, C.J.C.; SANTOS, F.C.A. Evolução da gestão ambiental na empresa: uma taxonomia integrada à gestão da produção e de recursos humanos. Gestão \& Produção, São Carlos, v.13, n.3, p. 435-448, set./dez. 2006.

KONZEN, E.A. Viabilidade Ambiental Econômica de Dejetos de Suinos. Sete Lagoas (MG): Embrapa Milho e Sorgo, 2006. 
NORTH, K. Environmental Business Management: an introduction. Genebra: International Labor Office (ILO), 1997.

OKONGWU, U.; MORIMOTO, R.; LAURAS, M. The maturity of supply chain sustainability disclosure from a continuous improvement perspective. International Journal of Productivity and Performance Management, Bingley, v. 62, n. 8, 2013.

OLIVEIRA, R.L.; MACHADO, A.G. Gestão ambiental empresarial: estudo de casos em empresas líderes dos setores supermercadistas e de refrigerantes. In: ENCONTRO DA ANPAD, 33., São Paulo, 2009.Anais... São Paulo: ANPAD, set.2009.

PALLINI, A. Controle biológico de pragas e seu uso em cultivos protegidos. Espaço do Produtor. Universidade Federal de Viçosa, 2009. Disponível em: $<$ https://www2.cead.ufv.br/espacoProdutor/scripts/verArtigo.php?codigo=21\&acao=exibir >. Acesso em: jan. 2014.

PENNA, C.G. Efeitos da mineração no meio ambiente. Associação O Eco, 26/01/2009. Disponível em: <http://www.oeco.org.br/carlos-gabaglia-penna/20837-efeitos-da-mineracaono-meio-ambiente>. Acesso em: jan. 2014.

PORTER, M.E.; VAN DER LINDE, C. Toward a new conception of the environmentcompetitiveness relationship. Journal of Economic Perspective, v. 9, n. 4, p. 97-118, Fall 1995.

PORTER, M. E. Estratégia Competitiva: técnicas para análise da indústria e da concorrência. Rio de Janeiro: Campus, 1991.

RODRIGUES, W. Análise dos determinantes dos investimentos ambientais no agronegócio: o caso da indústria frigorífica bovina goiana. Informe Gepec, Toledo, v. 11, n. 1, jan./jun. 2007.

SANCHES, C.L. Gestão ambiental proativa. Revista RAE, São Paulo, v. 40, n.1, jan./mar. 2000 .

SEIFFERT, M.E.B. Gestão ambiental: instrumentos, esferas de ação e educação ambiental. São Paulo: Atlas, 2010.

SHIGUNOV NETO, A.; CAMPOS, L.M.S.; SHIGUNOV, T.Fundamentos da Gestão Ambiental. Rio de Janeiro: Ciência Moderna, 2009.

SOKOLOVIC, S.M.; ZAVARGO, Z.Z.; SOKOLOVIC, D.S. Sustainable development, clean technology and knowledge from industry. Thermal Science, Belgrade, v. 16, Suppl. 1, 2012.

TRINDADE, S.P.; CHAVES, M.R. Sustentabilidade do setor sucroalcooleiro em Goiás: relação da produção agrícola e impactos ambientais. Trabalhos Completos. Rio de Janeiro: Universidade Federal Fluminense, 2008. Disponível em:

$<$ http://www.uff.br/vsinga/trabalhos/Trabalhos\%20Completos/Silas\%20Pereira\%20Trindade. pdf>. Acesso em: jan. 2014. 
WALTON, S.V.; HANDFIELD, R.B. The Green supply chain: integrating suppliers into environmental management processes. International Journal of Purchasing \& Materials Management,Amsterdam, v. 34, n.2, p. 2-11, Spring 1998.

XAVIER, K. D. et al. Coordenação e eficiência em agriclusteres de aves e suinos. Revista em Agronegócios e Meio Ambiente,Maringá, v.6, n.3, p.553-566, set./dez. 2013.

YIN, R. Estudo de Caso. 3. ed. Porto Alegre: Bookman, 2005. 